\title{
The Construction and Validation of the Arabic Scale of Intrinsic Religiosity (ASIR)
}

\author{
Ahmed M. Abdel - Khalek* \\ Department of Psychology, University of Alexandria, Egypt
}

Submission: July 06, 2017; Published: July 19, 2017

*Corresponding author: Ahmed M. Abdel-Khalek, Department of Psychology, University of Alexandria, Egypt; Email: aabdel-khalek@hotmail.com

\begin{abstract}
The aim of this study was to develop and validate the Arabic Scale of Intrinsic Religiosity (ASIR). This scale assesses internal religiosity regardless of any given religion or denomination. The ASIR consisted of 15 statements, to be answered with a five point intensity scale, anchored by 1 (Strongly Disagree) and 5 (Strongly Agree). A principal component analysis identified one high loaded factor. Cronbach alpha and test - retest reliabilities reached 0.91 and 0.87 respectively, indicating high internal consistency and temporal stability. Criterion - related validity ranged between 0.53 and 0.74 indicating acceptable to high validity. Descriptive statistics were available for university students from Egypt, Kuwait, and Algeria. The Algerian college students obtained the highest mean score on religiosity, then the Kuwaitis and the Egyptians. Female Egyptians obtained a significantly higher mean score than did their male counterparts. The ASIR was significantly correlated with positive psychology variables. A high - loaded factor was extracted and labeled "well-being and religiosity". The ASIR has Arabic and English equivalent forms. Based on the good psychometric properties of the ASIR, it was recommended to use it to assess intrinsic religiosity.

Keywords: Religiosity, Arabic Scale of Intrinsic Religiosity, reliability, validity, positive psychology
\end{abstract}

\section{Introduction}

Religion occupies a substantial role in people's lives across different cultures and it has been found to be a strong predictor of important life domains. Tarakeshwar et al. [1] suggested that humans be thought of as Homo religiosus because religion has been present as long as there have been Homo sapiens. Durkheim [2] maintained that groups, institutions, and cultures may represent their ideals through religious beliefs and practices. For different reasons, researchers are becoming increasingly interested in the examination of the impact of faith on human behavior and psychological functioning Jones [3]. Various positive contributions to overall physical and mental health have been attributed to religious devotion Abedel-Khalek [4-7] Lester [8] Koenig [9], Hill [10], Seybold [11].

People who report a closer connection to God experience a number of health-related benefits: less depression, higher self-esteem, less loneliness, greater relational maturity, greater psychological competence Hill [12], Koenig [9] stated that religious beliefs and practices are associated with: lower suicide rates, less anxiety, less substance abuse, less depression and faster recovery from depression, greater well-being, hope, and optimism, more purpose and meaning in life, higher social support, greater marital satisfaction and stability, better immune function, lower death rates from cancer, less heart disease or better cardiac outcomes, lower blood cholesterol, and better health behaviors (less cigarette smoking, more exercise, and better sleep). Religiosity reflects human characteristics or the amount of importance of religion in the life of a person Ellor [13]. Religiosity is a complex concept and has many definitions Holdcroft [14]. Different authors defined different dimensions of religiosity. To take some examples, Fukuyama [15] identified four dimensions of religiosity as cognitive, cultic, creedal, and devotional. Lenski [16] identified four different expressions of religiosity: associational, communal, doctrinal, and devotional. Glock [17] defined five dimensions of religiosity as follows: experiential, ritualistic, ideological, intellectual, and consequential. Allport [18] indentified two basic dimensions of religiosity: intrinsic and extrinsic. The extrinsically motivated persons use religion for their own ends, such as status, sociability, and self-justification, and often shape a creed to fit their own ends, so they use religion as a «means». This is a utilitarian outlook to religion. On the other hand, the person with intrinsic religiosity lives his religion and sees religion predominantly as an «end». These persons internalize the total creed of their faith, 


\section{Psychology and Behavioral Science International Journal}

find their master motive for life in religion, and brought their needs into harmony with their religious beliefs. In the English language, there are available many scales of religiosity AbuRaiya [19], Allport [20], Francis [21] Gorsuch [22], Hill and Hood [23] Koenig [24], Tiliouine [25].

The aim of the present study was to construct and validate the Arabic Scale of Intrinsic Religiosity (ASIR) on the basis of Allport [26] intrinsic dimension of religiosity. The ASIR assesses a generic internal religious experience. It could be used across religious traditions and not linked to specific religion. Why is this new scale needed? There are different reasons as follows: (a) some Arabic scales contain many items (e.g. 77) which is not suitable for the time of the respondent, (b) some scales merge items for the intrinsic and extrinsic dimensions of religiosity, (c) some scales are relevant to specific religions, e.g., Christianity or Islam in contrary to the ASIR; i. e., it is not linked to specific religious tradition, and (d) most of the available Arabic scales did not follow the four criteria for evaluating religiosity scales reported by Hill [12]: theoretical structure, representative sampling, measures of reliability, and measures of validity.

\section{Material and Method}

Participants: Through the different stages of the construction and validation of the ASIR, convenience volunteer samples were recruited (total $N=2,401$ ). They were college students from Egypt, Kuwait, and Algeria. Their ages ranged between 18 and 33 year.

\section{The construction of the scale}

The item pool: It was constructed on the basis of the experience of the present researcher and reviewing previous religiosity scales, e.g., Hill [12], Hoge [27], Plante [28], among other scales. A preliminary 41 positively worded statements were drafted in simple standard, and modern Arabic.

Item - remainder correlation: In computing the item-restof-test correlation, a sample of 165 college students of both sexes was tested using the 41 item scale. All the items with statistically significant correlations ( $\mathrm{p} \leq .001)$ over .30 and under .80 were retained. Fifteen items fulfilled that criterion. This version represents the final form of the ASIR (see the Appendix I).

Factor analysis: The final form of the ASIR was administered to 247 college students. The correlations between the 15 items were computed. Then, a principal component analysis was applied. Table 1 sets out the first factor. Inspection of table 1 indicates that the percentage of variance was $47 \%$ and the loadings onto the first component ranged between .54 and .79 .

\section{Results}

Internal consistency: Alpha Cronbach reliability of the 15 items $(\mathrm{N}=155)$ reached .91 , indicating high internal consistency.

Test - retest reliability: The one-week test-retest of the ASIR was .87 ( $\mathrm{N}=51)$, indicating good temporal stability.
Table 1: The first principal component of the ASIR.

\begin{tabular}{|c|c|c|}
\hline & Items & Factor 1 \\
\hline 1 & $\begin{array}{l}\text { I try hard to apply religion on the various } \\
\text { aspects of my life. }\end{array}$ & .680 \\
\hline 2 & $\begin{array}{l}\text { My worship to God Almighty is the most } \\
\text { important thing of my life. }\end{array}$ & .682 \\
\hline 3 & $\begin{array}{l}\text { My religious beliefs are behind my actions } \\
\text { and approach to life. }\end{array}$ & .724 \\
\hline 4 & $\begin{array}{l}\text { Religion is the most important thing in my } \\
\text { life. }\end{array}$ & .739 \\
\hline 5 & God helps me in my entire life. & .617 \\
\hline 6 & $\begin{array}{l}\text { My Religious beliefs are considered to be } \\
\text { necessary for me. }\end{array}$ & .735 \\
\hline 7 & $\begin{array}{l}\text { My faith gives me the meaning and the goal } \\
\text { of my life. }\end{array}$ & .787 \\
\hline 8 & I consider myself committed to religion. & .688 \\
\hline 9 & My faith is an integral part of my personality. & .695 \\
\hline 10 & I see my faith as a source of comfort for me. & .774 \\
\hline 11 & My faith affects many of my decisions. & .694 \\
\hline 12 & $\begin{array}{l}\text { I think that religion is an appropriate } \\
\text { approach to life. }\end{array}$ & .538 \\
\hline 13 & I believe that God is close to me. & .616 \\
\hline 14 & I depend on Almighty God in all things. & .617 \\
\hline 15 & $\begin{array}{l}\text { Religiosity gives me the strength to face the } \\
\text { difficulties of life. }\end{array}$ & .676 \\
\hline 16 & Eigen value & 7.08 \\
\hline 17 & $\%$ of variance & 47.20 \\
\hline
\end{tabular}

Citerion-related validity: The ASIR was administered along with the Muslim Attitude towards religionsity Scale MARS; Wilde [29] as well as the single item self - rating scale of religiosity (N1 = 140; $\mathrm{N} 2=45$, respectively). The correlations between the ASIR and the MARS were .74 and .72, and between the ASIR and the single item were .63 and .53 among men and women, respectively. All the correlations were statistically significant ( $\mathrm{p}$ $<.001$ ), indicating acceptable to high criterion-related validity. 
Table 2: Pearson product moment correlation between the scales and the first component among men and women $(N=293)$.

\begin{tabular}{|l|c|c|}
\hline \multicolumn{1}{|c|}{ Scales } & r with ASIR* & Factor I \\
\hline Internal Religiosity (ASIR) & - & .532 \\
\hline Mental Health & .389 & .925 \\
\hline Self - Efficacy & .318 & .794 \\
\hline Satisfaction with Life & .306 & .740 \\
\hline Optimism & .428 & .876 \\
\hline Love of life & .391 & .821 \\
\hline Well - Being & .240 & .645 \\
\hline Eigen value & & 4.170 \\
\hline \% of variance & & 59.630 \\
\hline \multicolumn{2}{|c|}{$*$ All the correlations $\mathrm{p}<.01}$. & \\
\hline
\end{tabular}

The association of the scale with positive psychology variables: The ASIR was administered along with the Arabic versions of the following scales: the Arabic Scale of Mental Health, the Arabic Scale of Optimism and the Love of Life Scale Abdel Khalek [30-32] the Arabic Scale of Self -Efficacy Alansari [33] the Satisfaction with Life Scale Diener [34], and the WHO (five) Well - being Index Psychiatric Research Unit [35]. A convenience sample of 293 college students (162 men; 131 women) was recruited. The Pearson correlation coefficients and the principal components analysis were computed. Table 2 presents the results. Inspection of Table 2 indicates that the correlations between the ASIR and the positive psychology scales ranged from .240 to $.428(\mathrm{p}<.01)$. The loadings onto the first component ranged between .532 (the ASIR) and .925 (mental health). This component was labeled "Well - being and religiosity".

Table 3: Mean (M), standard deviation (SD) of the ASIR, and $t$ value in three Arab samples.

\begin{tabular}{|c|c|c|c|c|c|c|c|}
\hline Country & $\mathbf{N}$ & $\mathbf{M}$ & SD & $\mathbf{N}$ & $\mathbf{M}$ & SD & $\mathbf{t}$ \\
\hline Egypt & 305 & 57.95 & 11.89 & 403 & 61.63 & 9.69 & $4.15^{*}$ \\
\hline Kuwait & 159 & 65.67 & 7.08 & 131 & 64.57 & 7.32 & 1.30 \\
\hline Algeria & 300 & 68.59 & 5.00 & 300 & 68.63 & 4.53 & 0.10 \\
\hline$* p<.01$
\end{tabular}

Normative data: The ASIR was administered to convenience samples of college students from three Arab countries (N =1,598): Egypt, Kuwait, and Algeria. Sofghalim [36] collected the data from Algeria. Table 3 presents the descriptive statistics and the $t$ values. Inspection of this table reveals that the only sex - related statistically significant difference was in the Egyptian sample in favor of women. Further, the sample from Algeria obtained the highest mean score, whereas the Egyptian sample obtained the lowest mean ASIR score. These results were relevant for both sexes.

\section{Discussion}

The great investment in matters of religion and spirituality is one of the main trends in contemporary psychology. One of the reasons for the interest in the study of religion is the salutary effects of religiosity on physical and mental health as well as health habits and longevity. Several studies obtained positive relationships between religiosity and subjective well - being including happiness, satisfaction with life and health. Measurement is a cornerstone of science and hence is a critical component of scientist investigations of religious phenomena. There were different reasons to construct the Arabic scale of Intrinsic Religiosity as reported in the introduction section.

All the 15 items of the ASIR are positive indicators to intrinsic religiosity. An affirmatively worded strategy was used in the construction of the ASIR because many participants face problems in understanding the negatively worded items when answering with double negative. Carver [37] maintained that «negatively worded items often turn out to be harder to understand or more complicated to answer than positively worded items» (p. 47). In a similar vein, Schriesheim [38] stated that negatively worded items impair response accuracy. As a remedy to the problem of understanding the double negatives, some researchers use negatively worded items (e.g., the sources of comfort for me are far from religion) in religiosity scales and then recode the responses. On the basis of the Baumeister [39] paper entitled: "Bad is stronger than good", this procedure is problematic as there is evidence that items describing negative emotions tend to evoke much stronger responses than items describing positive emotions. People tend to underestimate the frequency of positive effect, but not negative effect. The last authors concluded that "bad emotions generally produce more cognitive processing and have other effects on behavior that are stronger than positive emotions" (p. 334).

Despite the good characteristics of the ASIR, there is a need to use item response theory to develop a short form of the scale, to run confirmatory factor analysis, and determination of normative values for different age groups particularly the old aged. The English version of the ASIR merits investigation in an English-speaking sample. These are projects for further studies [40-44].

\section{Conclusion}

The present study successfully demonstrated its main objective. The Arabic Scale of Intrinsic Religiosity (ASIR) characterized with good to high internal consistency, temporal 
stability, and criterion - related validity. Therefore, it is safe to conclude that the ASIR has good psychometric properties. It has several advantages, beside its good psychometric characteristics, i. e., the brevity (15 items), so it is far from both

\section{References}

1. Tarakeshwar N, Stanton J, Pargament KI (2003) Religion: An overlooked dimension in cross-cultural psychology. Journal of CrossCultural Psychology 34: 377-394.

2. Durkheim E (1915) The elementary forms of the religious life. Free Press, New York, USA.

3. Jones SL (1994) A constructive relationship for religion with the science and profession of psychology: Perhaps the boldest model yet. American Psychologist 49(3): 184-189.

4. Abdel-Khalek AM (2010) Quality of life, subjective well-being and religiosity in Muslim college students. Qual Life Res 19(8): 1133-1143.

5. Abdel-Khalek AM (2011) Subjective well-being and religiosity in Egyptian college students. Psychological Reports 108: 54-58.

6. Abdel-Khalek AM (2012) Associations between religiosity, mental health and subjective well-being among Arabic samples from Egypt and Kuwait. Mental Health, Religion and Culture 15(8): 741-758.

7. Abdel-Khalek AM (2012) Subjective well-being and religiosity: A crosssectional study with adolescents, young and middle-age adults. Mental Health, Religion and Culture 15(1): 39-52.

8. Abdel-Khalek AM, Lester D (2013) Mental health, subjective wellbeing, and religiosity: Significant associations in Kuwait and USA. Journal of Muslim Mental Health 7(2): 63-76.

9. Koenig HG (2004) Religion, Spirituality, and medicine: Research findings and implications for clinical practice. South Med J 97(12): 1194-1200.

10. Hill PC, Pargament KI (2003) Advances in the conceptualization and measurement of religion and spirituality: Implications for physical and mental health research. Am Psychol 58(1): 64-74.

11. Seybold KS (2007) Physiological mechanisms involved in religiosity/ spirituality and health. Journal of Behavioral Medicine 30: 303-309.

12. Hill PC (2005) Measurement in the psychology of religion and spirituality: Current status and evaluation. In RF Paloutzian \& CL Park (Eds.), Handbook of the psychology of religion and spirituality (pp. 4361) The Guilford Press, USA.

13. Ellor JW, McGregor JA (2011) Reflections on the words "religion", "Spiritual well-"being", and "spirituality". Journal of Religion, Spiritual, and Aging 23: 275-278.

14. Holdcroft B (2006) What is religiosity? Catholic Education: A Journal of Inquiry and Practice, 19: 89-103.

15. Fukuyama Y (1960) The major dimensions of church membership. Review of Religious Research 2: 154-161.

16. Lenski G (1963) The religious factor. Garden City: Doubleday Pargament KI (1997) The psychology of religion and coping: Theory, research, practice, Guilford Press, New York, USA.

17. Glock CY, Stark R (1965) Religion and society in tension. San Francisco: Rand McNally.

18. Allport GW, Ross JM (1967) Personal religious orientation and prejudice. J Pers Soc Psychol 5: 432-443.

19. Abu Raiya H, Pargament KI, Mahoney A, Stein C (2008) A psychological measure of Islamic religiousness: Development and evidence for reliability and validity. The International Journal for the Psychology of Religion 18: 291-315. the very brief measures with the single item self-rating scales, and the very long scales of religiosity (up to 77 items). The ASIR is straightforward in assessing only a single dimension: Intrinsic religiosity, regardless of a given religion or denomination.

20. Allport GW (1950) The individual and his religion. Macmillan, New York, USA.

21. Francis LJ, Stubbs MT (1987) Measuring attitudes towards Christianity: From childhood to adulthood. Personality and Individual Differences 8: 741-743.

22. Gorsuch RL (1984) Measurement: The boon and bane of investigating religion. American Psychologist 39: 228-236.

23. Hill PC, Hood Jr RW (1999) Measures of religiosity. AL Religious Education Press, England.

24. Koenig HG, Büssing A (2010) The Duke University Religion Index (DUREL): A five-item measure for use in epidemiological studies. Religions 1: 78- 85.

25. Tiliouine $\mathrm{H}$ (2009) Measuring satisfaction with religiosity and its contribution to the Personal Well-Being Index in a Muslim sample. Applied Research in Quality of Life 4: 91-108.

26. Allport GW (1959) Religion and prejudice. Crane Review 2: 1-10.

27. Hoge DR (1972) A validated intrinsic religious motivation scale. Journal of the Scientific Study of Religion 11(4): 369-376.

28. Plante TG, Boccaccini MT (1997) The Santa Clara Strength of Religious Faith Questionnaire. Pastoral Psychology 45: 375-387.

29. Wilde A, Joseph S (1997) Religiosity and personality in a Muslim context. Personality and Individual Differences 23: 899-900.

30. Abdel Khalek AM (1996) Manual for the Arabic Scale of Optimism and Pessimism. Alexandria, Egypt.

31. Abdel-Khalek AM (2007) Love of life as a new construct in the wellbeing domain. Social Behavior and Personality 35: 125-134.

32. Abdel-Khalek AM (2011) The development and validation of the Arabic Scale of Mental Health (ASMH). Psychological Reports 109: 949-964.

33. Al Ansari HA, Abdel-Khalek AM (2012) Religiosity and its relationship with self-efficacy and anxiety among three Kuwaiti samples. Derasat Nafsiyah 22 (1): 149-180.

34. Diener E, Emmons RA, Larsen RJ, Griffin S (1985) The Satisfaction with Life Scale. J Pers Assess 49: 71-75.

35. Psychiatric Research Unit, WHO Collaborating Centre in Mental Health (1998) WHO (Five) well-being Index. Frederiksberg General Hospital, Hillerod, Denmark.

36. Sofghalim IO (2015) Religiosity and its relation to mental health and negative thinking. Unpublished Master degree, Alexandria University, Egypt.

37. Carver CS, Scheier MF (2000) Perspectives on personality (4 $4^{\text {th }}$ ed.). Boston: Allyn \& Bacon.

38. Schriesheim CA, Hill KD (1981) Controlling acquiescence response bias by item reversals: The effect on questionnaire validity. Educational and Psychological Measurement 41: 1101-1114.

39. Baumeister RF, Bratslavsky E, Finkenauer C, Vohs KD (2001) Bad is stronger than good. Review of General Psychology 5: 323-370.

40. Abdel-Khalek AM (2006) Happiness, health, and religiosity: Significant relations. Mental Health, Religion and Culture 9(1): 85-97.

41. Abdel-Khalek AM (2007) Assessment of intrinsic religiosity with a single item measure in a sample of Arab Muslims. Journal of Muslim Mental Health 2: 211-215. 


\section{Psychology and Behavioral Science International Journal}

42. Albright CR, Ashbrook JB (2001) Where God lives in the human brain. Naperville, USA.

43. Gorsuch RL, McPherson SE (1989) Intrinsic/ extrinsic measurement: I/ERevised and single item scales. Journal for the Scientific Study of
Religion 28: 348-354.

44. Koenig HG, King DE, Carson VB (2012) Handbook of religion and health ( $2^{\text {nd }}$ ed.) Oxford University Press, USA.

\section{Appendix - I}

Instructions: The following statements related to religious attitudes. Please answer each one, based on the following scale starts from Strongly Disagree to the Strongly Agree. Put a circle around one of the numbers following each statement.

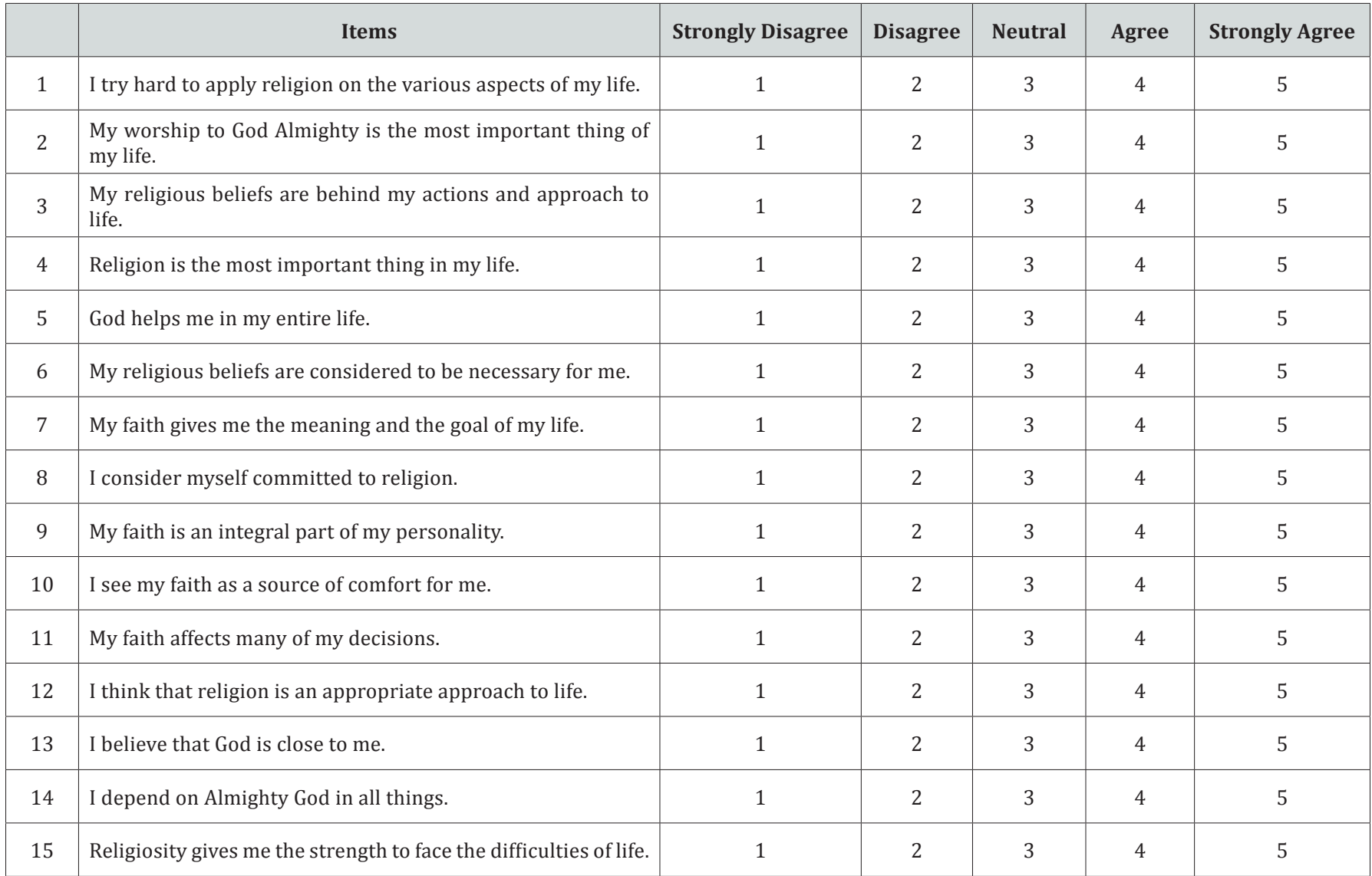

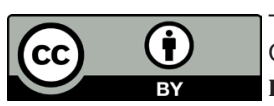

This work is licensed under Creative Commons Attribution 4.0 License

DOI: $10.19080 /$ PBSIJ.2017.04.555644

\section{Your next submission with Juniper Publishers} will reach you the below assets

- Quality Editorial service

- Swift Peer Review

- Reprints availability

- E-prints Service

- Manuscript Podcast for convenient understanding

- Global attainment for your research

- Manuscript accessibility in different formats

( Pdf, E-pub, Full Text, Audio)

- Unceasing customer service

Track the below URL for one-step submission https://juniperpublishers.com/online-submission.php 